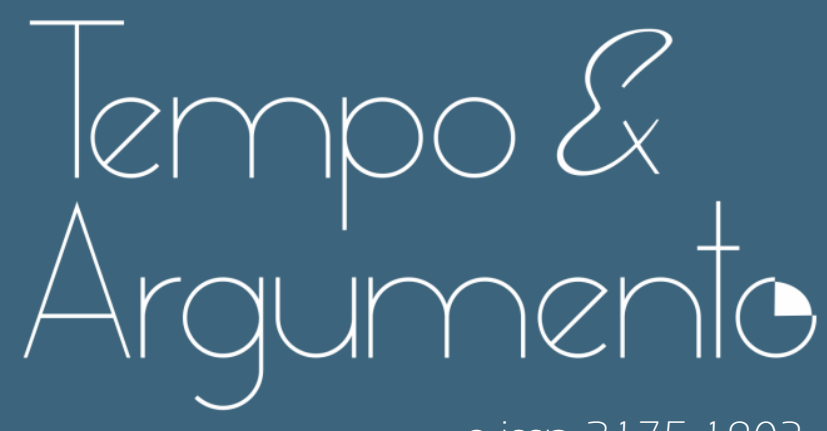

e-issn 2175-1803

\title{
Epistemologia insubmissa feminista negra decolonial
}

- Angela Figueiredo

Doutora em Sociologia pelo Instituto Universitário de Pesquisas do Rio de Janeiro (IUPERJ). Professora do Programa de Pós-Graduação em Ciências Sociais (PPGCS) e Coordenadora do Grupo de Pesquisa em Gênero, Raça e Subalternidade (Coletivo Angela Davis) da Universidade Federal do Recôncavo da Bahia (UFRB). Professora do Programa de Pós-Graduação em Estudos Étnicos e Africanos da Universidade Federal da Bahia (POSAFRO/UFBA) e do (PPGNEIM/UFBA). Integrante do Fórum Marielle.

Cachoeira, BA - BRASIL lattes.cnpq.br/6332981346537949

angelaf39@gmail.com)

(D) orcid.org/0000-0003-3803-0355

Para citar este artigo:

FIGUEIREDO, Angela. Epistemologia insubmissa feminista negra decolonial. Tempo e Argumento, Florianópolis, v. 12, n. 29, e0 102 , jan./abr. 2020.

dof http://dx.doi.org/10.5965/21751803122292020e0 102

Recebido: 23/09/2019

Aprovado: 23/03/2020 


\title{
Epistemologia insubmissa feminista negra decolonial
}

\begin{abstract}
Resumo
Neste texto, propomos uma revisão/análise das abordagens teórico-metodológicas do feminismo nos últimos anos. Destacamos que a epistemologia feminista negra articula teoria, metodologia e prática política com vistas à transformação social. A análise realizada revela um diálogo constante entre o feminismo negro brasileiro e o feminismo afro-americano, ainda que as editoras brasileiras só tenham traduzido a contribuição feminista negra e descoberto este filão comercial nos últimos cinco anos. A popularização do conceito de interseccionalidade no Brasil é relativamente recente para um conceito que fez 30 anos, sendo atualmente o mais utilizado aqui para analisar as relações e as interconexões possíveis entre as categorias de gênero, raça, classe, sexualidade, geração etc. É importante destacar o significativo crescimento das pesquisas, livros e artigos acadêmicos produzidos por mulheres negras, bem como a divulgação de ideias e reflexões políticas através do uso das plataformas digitais, tais como sites, blogs, facebook, Instagram e YouTube. Este movimento, que algumas autoras têm definido como a quarta onda feminista, mas que algumas mulheres negras preferem chamar de maré feminista negra, ampliou o referencial teórico, incluindo as contribuições de autoras africanas e afrodiaspóricas, como por exemplo, Oyèrónkẹ Oyěwùmí (2017) e Grada Kilomba (2019), e recuperou contribuições negras, notadamente femininas negras que foram historicamente silenciadas, através de práticas epistemicidas, construindo desse modo uma nova epistemologia feminista negra.
\end{abstract}

Palavras-chave: Epistemologia. Movimento social. Feminismo negro. Empoderamento. Descolonização.

\section{Decolonial, black and unsubmissive feminist epistemology}

\begin{abstract}
In this text we aim to present a review/analysis of the theoretical and methodological approaches towards feminism in recent years. We emphasize that the black feminist episthemology articulates theory, methodology and political practice aiming social transformation. The analysis which was carried out reveals a constant dialogue between Brazilian black feminism and African-American feminism, even though Brazilian publishing houses have only translated the black feminist contribution and discovered its comercial streak during the last five years. The popularization of the concept of intersectionality in Brazil is relatively recent for a concept that turned 30 years old, being currently the most used here to analyze possible interconnections between the categories of gender, race, social class, sexuality, generation, etc. It's important to highlight the significant growth of researches, books and academic articles produced by black women, as well as the raising dissemination of political ideas and reflections through the use of digital platforms, such as websites, blogs, Facebook, Instagram and Youtube. This movement, which some of its authors has defined as the fourth feminist wave, but which some black women prefer to call it the black feminist tide, has broadened the theoretical framework, including the contributions of African and African-diasporic authors, such as Oyèrónkẹ Oyěwùmí (2017) and Grada Kilomba (2019). It recovered black contributions, particularly black women who were historically silenced, through epistmied practices, thus building a new black feminist epistemology.
\end{abstract}

Keywords: Epistemology. Social movement. Black feminism. Empowerment. Decolonization. 
Este texto é originário de uma provocação inicial para participar de uma mesa intitulada "Epistemologias Insubmissas", realizada durante o $13^{\circ}$ Fórum Social Mundial, ocorrido em Salvador, a convite do grupo intitulado "Diálogos Insubmissos de Mulheres Negras". A mesa ocorreu exatamente um dia após o assassinato de Marielle Franco, em 14 de março de 2018 e, passados 18 meses do cruel assassinato, ainda não sabemos o nome dos mandantes desse crime, por isso é ainda necessário perguntar: Quem mandou matar Marielle? Eu agradeço a oportunidade e o estímulo propiciado pelo convite de Dayse Sacramento, que me permitiu sistematizar uma série de reflexões oriundas dos encontros no Coletivo Angela Davis/UFRB, da Escola Internacional feminista Negra e Decolonial e das intervenções práticas em parceria com o ODARA e no Fórum Marielle em torno da formulação e conceptualização de uma Epistemologia Insubmissa Feminista Negra Decolonial. O título da mesa tem uma clara referência à antologia "Insubmissas lágrimas de mulheres", de Conceição Evaristo (2017) ${ }^{1}$, composta por 13 contos protagonizados por mulheres negras que narram suas dores, anseios, temores e resistência.

O diálogo que proponho neste texto busca resgatar reflexões sobre os percursos teórico-metodológicos do feminismo negro realizados nos últimos anos $^{2}$, destacando as principais mudanças e apontando alguns fatores que contribuíram para a emergência de uma nova epistemologia feminista negra. 0 contexto político e social em que tais movimentos se inscrevem é, efetivamente, propiciado pelas conquistas do movimento negro a partir dos anos de 1980, atrelado às políticas sociais implementadas pelo governo petista, tais como, a expansão do número de universidades públicas e a implementação das políticas de ações afirmativas, possibilitando que um maior número de professores e alunas e alunos negros adentrassem a universidade. Esse ingresso contribuiu para a formação de coletivos negros dentro e fora das universidades, que efetivamente estreitaram laços e alianças com os movimentos sociais, notadamente o movimento de mulheres negras.

\footnotetext{
1 EVARISTO, Conceição. Insubmissas lágrimas de mulheres. Rio de Janeiro: Editora Malê, 2017.

2 Neste texto, utilizo os termos "movimento de mulheres negras" e "feminismo negro" como sinônimos, ainda que saibamos que, no passado, muitas mulheres negras integrantes do movimento de mulheres se recusavam a serem identificadas como feministas (PONS, 2002; FIGUEIREDO; GOMES, 2016).
} 
Além disso, o crescimento e a diversidade do movimento feminista contemporâneo foram definidos por algumas autoras como a quarta onda feminista (HOLANDA, 2018). Nas palavras de Lélia Gonzalez:

É inegável que o feminismo como teoria e prática vem desempenhando um papel fundamental em nossas lutas e conquistas, e à medida que, ao apresentar novas perguntas, não somente estimulou a formação de grupos e redes, mas também desenvolveu a busca de uma nova forma de ser mulher. (GONZALEZ, 2011, p. 12).

O acúmulo de dados sobre as desigualdades raciais e de gênero produzidas dentro e fora da academia e a constante denúncia e ações de conscientização realizadas pelo movimento de mulheres negras, atrelados às já mencionadas conquistas feministas, criou um cenário de maior sensibilidade às desigualdades raciais e de gênero, que associadas ao uso de plataformas digitais, dão origem ao ciberativismo feminista negro. Essas mudanças formaram o amálgama necessário para eclodir um movimento de mulheres negras, plural e diverso. Somos muitas e atuantes em diferentes áreas profissionais e sociais. Somos conscientes de que o feminismo negro historicamente foi e ainda é produzido fora da academia, pois as mulheres negras encontraram na música, na poesia e nas artes em geral uma forma de expressar os seus sentimentos, aprendizados, ensinamentos e reflexões sobre a vida (COLLINS, 2017).

Testemunhamos o aumento significativo do feminismo negro e suas diferentes perspectivas: são as feministas negras decoloniais, feministas negras abolicionistas, feministas negras interseccionais, feministas negras lésbicas, dentre outros. Esse movimento tem sido autodefinido pelas mulheres negras em Salvador como maré feminista negra, uma clara alusão à divisão das três fases que caracterizam o feminismo em ondas; ao mesmo tempo em que se constitui enquanto uma ruptura, uma vez que as diferentes ondas feministas não incluíram, em nenhuma de suas fases, a contribuição feminista negra.

Do ponto de vista da experiência acadêmica, há um movimento político decolonial que pressiona professoras e professores a incorporarem na bibliografia dos cursos ministrados autoras e autores negros e africanos. Eles reconhecem a geopolítica do conhecimento que historicamente privilegiou e 
reproduziu o conhecimento hegemônico e eurocêntrico, rejeitando a continuidade de práticas epistemicidas.

Anibal Quijano afirma:

A elaboração intelectual do processo de modernidade produziu uma perspectiva de conhecimento e um modo de produzir conhecimento que demonstram o caráter do padrão mundial de poder: colonial/moderno, capitalista e eurocentrado. Essa perspectiva e modo concreto de produzir conhecimento se reconhecem como eurocentrismo. (QUIJANO, 2000, p. 115).

Sobre o epstemicídio, Sueli Carneiro observa que é

[...] um conceito extraído da reflexão de Boaventura Sousa Santos (1995), que integramos ao dispositivo de racialidade/biopoder como um dos seus operadores por conter em si tanto as características disciplinares do dispositivo de racialidade quanto as de anulação/morte do biopoder. É através desse operador que este dispositivo realiza as estratégias de inferiorização intelectual do negro ou sua anulação enquanto sujeito de conhecimento, ou seja, formas de sequestro, rebaixamento ou assassinato da razão. Ao mesmo tempo, e por outro lado, o faz enquanto consolida a supremacia intelectual da racialidade branca. (CARNEIRO, 2005, p. 10).

Uma análise do ponto vista teórico revela um constante diálogo do feminismo negro brasileiro com o afro-americano, ainda que as editoras brasileiras só tenham traduzido a contribuição feminista negra estadunidense e descoberto esse filão comercial nos últimos cinco anos. O livro de Angela Davis, “Mulheres, Raça e Classe”, originalmente publicado em 1981, somente teve sua edição brasileira em 2016, e o sucesso de venda dessa primeira tradução estimulou a editora a traduzir outros livros da mesma autora. Muitas de nós já tínhamos lido esse mesmo livro em português, graças a uma tradução feita pelo movimento de mulheres de Portugal.

Algumas intelectuais e ativistas brasileiras, como Luíza Bairros, foram responsáveis pela tradução, no sentido mais amplo do termo, das importantes contribuições de feministas afro-americanas. Patricia Hill Collins, por exemplo, nos foi apresentada por Luíza Bairros (1995) no artigo Nossos Feminismos Revisitados, em que a autora propõe uma articulação entre as nossas experiências e a perspectiva apresentada pela intelectual afro-americana na 
análise de um programa culinário de televisão, em que a mulher negra é subordinada a uma mulher branca. A autora apresenta alguns conceitos fundamentais do feminismo, como por exemplo, os de experiência e de ponto de vista, e destaca a contribuição de Patrícia Hill Collins na formulação de uma perspectiva teórica feminista negra que desafia

[...] ideias hegemônicas da elite masculina branca expressando uma consciência sobre a intersecção de raça e classe na estruturação de gênero. Tal tradição constituiu-se em torno de cinco temas fundamentais que caracterizariam o ponto de vista feminista negro: 1) o legado de uma historia de luta; 2) a natureza interligada de raça, gênero e classe; 3) o combate aos estereótipos ou imagens de controle; 4) a atuação como mães, professoras e líderes comunitárias; 5) e a politica sexual. (BAIRROS, 1995, p. 462).

Posteriormente, o livro de Collins, Black Feminist Thought, circulou entre nós na sua edição em inglês, tornando-se uma leitura obrigatória nos cursos de graduação, pós-graduação e nos espaços não institucionalizados de aprendizado, para tod@s nós. O investimento em traduções de obras importantes de feministas afro-americanas não tem inspirado as grandes editoras a publicarem textos de autores negros brasileiros, homens e mulheres. Ao contrário, o que presenciamos hoje é o significativo aumento de pequenas editoras voltadas para a publicação de obras de autores negros e negras.

Um exemplo paradigmático disso é a coleção Feminismos Plurais, organizada por Djamila Ribeiro. Os livros publicados por essa coleção popularizam temas que são tratados na academia, subvertendo a lógica de citações acadêmicas. Numa atitude subversiva, as jovens feministas negras optam por citar a releitura de temas considerados clássicos, tal como a o conceito de conhecimento situado, de Donna Haraway (2004), ou mesmo de Gayatri Spivak (2010), em “Pode o subalterno falar?”, mas que ficou popularmente conhecido nos últimos dois anos como "Lugar de Fala”, de Djamila Ribeiro (2017).

Com relação ao sucesso das publicações e ao consumo de obras de mulheres negras, Collins, referindo-se ao contexto americano observa que:

Mas as mulheres afro-americanas agora estão diante de um momento histórico diferente. As mulheres negras parecem ter uma voz, e com essa voz recém-descoberta vem uma nova série 
de preocupações. Por exemplo, devemos estar atentas à absorção sedutora das vozes das mulheres negras em salas de aula no ensino superior, onde os textos de mulheres negras ainda são muito mais bem-vindos do que a presença das mulheres negras em si. (COLLINS, 2017, p. 3).

Levando em conta este propósito, este artigo está estruturado em três seções: na primeira, tratamos do debate sobre a epistemologia ocidental e das críticas realizadas pelo feminismo, pelo feminismo negro e pela perspectiva decolonial no século passado, pois, estas são bases fundamentais para a emergência de novas epistemologias neste novo milênio. Na segunda, abordamos aspectos teóricos e conceitos importantes do feminismo negro. No terceiro momento, retomamos a relação entre as teorias decoloniais e feministas negras, como marcos teóricos importantes para a emergência de uma desobediência epistêmica, como propõe Walter Mignolo (2008).

\section{Por uma nova epistemologia feminista negra decolonial}

Em primeiro lugar, gostaríamos de recuperar a própria definição de epistemologia. De acordo com o dicionário, a epistemologia é:

[...] o ramo da filosofia que trata da natureza, etapas e limites do conhecimento humano, especialmente nas relações que estabelecem entre o sujeito e o objeto do conhecimento. Nesse sentido, pode ser também chamada de teoria do conhecimento. Em sentido mais restrito, refere-se às condições sob as quais se pode produzir o conhecimento científico e dos modos para alcançá-lo, avaliando a consistência lógica de teorias. (NAIME, 2018, não paginado).

E “insubmissão é rebeldia; ausência de submissão; qualidade de quem não se submete. Desobediência; comportamento que denota insubordinação. Particularidade ou atributo do que é insubmisso"3.

De acordo com Boaventura (2009), a epistemologia construiu um modelo hegemônico de ciência moderna, oriundo do modelo de racionalidade que se constituiu a partir da revolução científica do século XVI, e que alcançou seu apogeu no século XIX. Uma das características mais destacada nesse contexto

\footnotetext{
${ }^{3}$ Dicionário on line de português. Disponível em: <https://www.dicio.com.br/insubmissao/>. Acesso em: 10 de set. 2019 .
} 
foi a omissão do sujeito na produção do conhecimento, que "esqueceu" trabalhadores, mulheres, indígenas, afrodescendentes, e esses excluídos e excluídas estão, sobretudo, no conjunto de países e regiões submetidos ao colonialismo europeu (SANTOS, 2009).

Sabemos, contudo, que a indagação sobre a condição do sujeito na produção do conhecimento é um dos grandes aportes do feminismo à ciência (HARDING, 1987. Conhecimento situado é uma das contribuições de Donna Haraway (1995 à epistemologia, pois, a autora destaca que falamos sempre de um lugar nas relações sociais de poder. Enquanto Patrícia Hill Collins (1990) fala da teoria do ponto de vista, pois considera não apenas o gênero, mas também a raça na constituição do sujeito que produz conhecimento, neste caso, a autora coloca o ponto de vista das mulheres negras.

O que destacamos agora é que não somente o gênero, a raça, a classe, e também a sexualidade, são elementos determinantes na configuração desses novos sujeitos ou novas sujeitas na produção do conhecimento. Destaquei a palavra sujeita, visto que essa atitude tem sido mais do que uma reinvindicação, é uma prática política voltada para feminilizar e enegrecer a linguagem nos textos produzidos por autoras e autores negros neste novo milênio. Reinvindicamos também enegrecer as referências bibliográficas - procedendo de maneira análoga aos textos feministas que reconhecidamente transformaram as regras de citações, ao incluir o primeiro nome das mulheres citadas nos artigos, para fazer frente à certa masculinização das referências bibliográficas, quando apenas os sobrenomes são citados - colocando em negrito o sobrenome para indicar que aquelas são contribuições de autoras e autores negros. Desse modo, subvertemos a regra; para nós será DAVIS, Angela, por exemplo.

Como destaquei em outros trabalhos (FIGUEIREDO, 2018), o aspecto prioritário presente no debate sobre posicionalidade, e sobre o lugar do sujeit@ na produção do conhecimento, é o lugar da enunciação, isto é, a localização de nacionalidade, étnica ou racial, de classe e de gênero do sujeito que enuncia. Nas epistemologias ocidentais, o sujeito que falava estava sempre encoberto, pois isso assegurava o suposto mito da neutralidade. 
Esta estratégia epistêmica tem sido crucial para os desenhos imperiais/globais ocidentais e para a hegemonia dos brancos crioulos nas Américas. Por meio do encobrimento da localização particular do sujeito de enunciação, foi possível, para a expansão e a dominação coloniais europeias/euro-norte-americanas e para - poder das elites euro-latino-americanas, construir uma hierarquia do conhecimento superior versus conhecimento inferior e, portanto, de seres superiores versus seres inferiores no mundo. (FIGUEIREDO, 2017a, p. 93)

Além disso, Collins (2000) faz uma distinção operacional entre os termos epistemologias, paradigmas e metodologias:

[...] em contraste com as epistemologias, os paradigmas abrangem enquadramentos interpretativos, como a interseccionalidade, que são usados para a explicação de tal fenômeno social. Metodologia se refere aos princípios gerais de como conduzir uma pesquisa e como paradigmas interpretativos devem ser utilizados. O nível da epistemologia é importante porque ele determina quais questões merecem investigação, que quadros interpretativos serão utilizados para analisar os achados e que conhecimento subsequente será expresso. (COLLINS, 2000, p. 252).

Experiência é um conceito importante para o feminismo e para o feminismo negro. "O pessoal é político", uma das importantes contribuições do feminismo revela o elo entre a experiência pessoal, individual e coletiva. De acordo com Collins (2000), a experiência é a base fundamental da epistemologia feminista negra.

Como destacado acima, a experiência pessoal, a experiência vivida e compartilhada é para nós, pesquisadores e pesquisadoras negras, uma evidência muito importante, já que é a base de nossa reflexão e teorização. Nesse sentido é que a metodologia proposta pelo feminismo negro destaca o diálogo mais horizontal, a empatia e, muitas vezes, a autoetnografia como método prioritário de pesquisa.

Corroborando o nosso argumento, o exemplo de Thais Aguiar (2018), na sua dissertação de mestrado, é bastante contundente:

E por fim, outra característica que orienta o meu trabalho é a autoetnografia. A minha relação direta com o campo pesquisado não diminui o potencial acadêmico, muito pelo contrário, me possibilita incorporar experiências próprias, visando a 
problematização e análise sócio antropológica do contexto em que estou inserida. [...]

A Dissertação que aqui apresento foi construída a partir das indagações sobre as minhas experiências que vem me constituindo enquanto negra e universitária brasileira, e em diálogo com outras negras, situadas em outros espaços e portadoras de outras experiências, subjetivas e sociais. Portanto, vou começar descrevendo um pouco sobre a minha trajetória de vida e como isso influenciou na minha relação com o tema desta pesquisa, tema este que será apresentado no decorrer do texto. (AGUIAR, 2018, p. 1).

Ainda que reconheçamos que para o feminismo negro e para a comunidade negra o conhecimento não é só produzido na academia, o ingresso de estudantes negras e negros, de estudantes de comunidades tradicionais e de camadas populares nas universidades tem alterado as agendas de investigação/pesquisa, uma vez que a maioria d@s estudantes elege temas próximos, muitas vezes relacionados ao próprio cotidiano.

Há, efetivamente, uma correlação entre a experiência de vida, a experiência profissional e a escolha do tema de pesquisa. Ou seja, na medida em que a universidade pretende se tornar mais inclusiva, as questões de pesquisa se tornam mais próximas do universo empírico da pesquisadora. Dito de outro modo, na maioria das vezes a escolha do tema de pesquisa está muito próxima das atividades profissionalmente realizadas por el@s: por exemplo, é muito comum que professoras do ensino fundamental escolham como tema de pesquisa a escola, ao passo que membros de comunidades tradicionais preferem realizar estudos sobre suas comunidades.

Em minha experiência como professora negra, as pesquisas realizadas por essa nova geração têm sido cada vez mais uma investigação que busca oferecer respostas aos problemas encontrados em suas comunidades; conhecer, para intervir e transformar, é uma das características dessa nova geração sendo, neste caso, feministas ou não.

A nossa realidade desafia qualquer perspectiva de ciência conservadora e neutra. Como pensar na existência de um conhecimento que não esteja voltado para a compreensão de dinâmicas sociais que perpetuam as desigualdades e asseguram privilégios para uma minoria? Como aceitar e, de certo modo, reproduzir conceitos e teorias que em nada nos ajudam em termos de construir 
uma ciência comprometida com a transformação social. Então, foi exatamente a partir desses desafios, resultantes de uma realidade que se impõe e desafia a estagnação dos conceitos e teorias que essa geração de feministas negras tem reagido, criado um constante diálogo dentro e fora da academia. Falar com tem substituído o falar sobre.

Certamente, há uma representação que insiste em nos colocar como pouco habilidosos para a realização da reflexão acadêmica, independentemente dos numerosos casos de sucesso de estudantes e pesquisadores negros e negras. Contudo, o êxito pessoal não altera as representações coletivas; no máximo, nosso êxito é considerado uma exceção à regra. Assim como as perspectivas teóricas da colonialidade do poder, estamos criando novas perspectivas epistemológicas, teóricas e metodológicas.

\section{Recuperando algumas abordagens teóricas do feminismo negro}

Historicamente, a contribuição de Angela Davis no Brasil ocorreu muito mais em função de sua importância política e pelo projeto de liberdade que representa, do que pela incorporação de suas reflexões teóricas nas pesquisas, ainda que saibamos que, para o ativismo negro, teoria e prática caminham lado a lado. As reflexões de Angela Davis (2016) contestam a construção homogeneizante da categoria mulher, pois para ela, durante a escravidão, as mulheres negras foram, acima de tudo, trabalhadoras. Davis (2017) também critica a associação direta entre o significado da maternidade como elemento definidor da categoria mulher. Remetendo-se à experiência das plantations, a autora descreve o modo como a maternidade entre as mulheres escravas não se constituiu em nenhum tipo de "privilégio" ou de fragilidade, visto que as mulheres negras escravizadas, independentemente de estarem grávidas ou amamentando, trabalhavam da mesma forma que os homens nas lavouras.

Do mesmo modo que a impactante crítica de Davis ao complexo prisional industrial e a reinvindicação da abolição do sistema prisional ecoam com força na mobilização política atual. A autora toma como metáfora o abolicionismo e, baseada em Frederick Douglas, argumenta que o fim da escravidão não poderia ocorrer simplesmente com o desmantelamento da instituição escravidão, a partir 
da proclamação da 13a ementa da Constituição (Davis, 2019). De acordo com a autora, todo o sistema social e político precisava mudar para que fosse possível incorporar os ex-escravos em uma nova democracia, e isso não aconteceu, concluindo que a democracia dos EUA era uma democracia elitista, voltada para beneficiar os homens brancos e ricos.

Coincidentemente ou não, Lélia Gonzalez faz uma análise similar àquela conduzida por Angela Davis:

[...] o texto da lei de 13 de maio de 1988 (conhecida como Lei Áurea), simplesmente declarou como abolida a escravização, revogando todas as disposições contrarias e... nada mais. Para nós, mulheres negras e homens negros, nossa luta pela liberdade começou muito antes desse ato de formalidade jurídica e se estende até hoje. (GONZALEZ, 1983, p. 12).

Como já mencionado aqui, a popularização do conceito de interseccionalidade no Brasil é relativamente recente para um conceito que fez 30 anos, sendo atualmente o conceito mais utilizado para analisar as relações e interconexões possíveis entre as categorias de gênero, raça, classe, sexualidade, geração etc. nos últimos cinco anos. O conceito de interseccionalidade, tal como formulado pela feminista afro-americana Kimberlé Crenshaw (2002, p. 177), trata da "[...] forma pela qual o racismo, o patriarcalismo, a opressão de classe e outros sistemas discriminatórios criam desigualdades básicas que estruturam as posições relativas de mulheres, raças, etnias, classes e outras".

Sabemos que o conceito reflete uma longa história de formulação teórica, resultante da busca e da formulação de conceitos que expressem a experiência das mulheres negras, a exemplo de Sojourner Truth que, em 1851, profere o seu famoso discurso em que faz a crítica: “Ain’t a Woman?” ("E não sou uma mulher?” - [2018]). Uma tradição continuada por Anna Julia Cooper (1892), que identifica as mulheres negras como importantes agentes da mudança social.

Como destacado em outro texto, o conceito de interseccionalidade tem sido uma ferramenta teórica e política útil de análises realizadas por nós, feministas negras brasileiras. 
Do ponto de vista da visualização do conceito, a imagem do entrecruzamento de avenidas, proposta por Crenshaw (2002), é muito mais próxima do nosso referencial, pois uma intersecção é também uma encruzilhada - espaço de referência significativa para as religiões afro-brasileiras. A encruzilhada é um lugar de encontro, mas é também um espaço de múltiplas saídas, lugares, caminhos, ruas e estradas. A encruzilhada é um dos importantes locais onde se coloca oferenda para Exú, o mensageiro entre os diferentes mundos no candomblé. (FIGUEIREDO; GOMES, 2016, p. 912)

Angela Davis (2018) considera que o feminismo negro vai além da análise interseccional das categorias de gênero raça e classe, pois

Ele deve envolver uma consciência em relação ao capitalismo, ao racismo, ao colonialismo, às pós-colonialidades, às capacidades físicas, a mais gêneros do que jamais imaginamos, a mais sexualidades do que pensamos poder nomear. O feminismo não nos ajudou apenas a reconhecer uma série de conexões entre discursos, instituições, identidades e ideologias que tendemos a examinar separadamente. Ele também nos ajudou a desenvolver estratégias epistemológicas e de organização que nos levam além das categorias "mulher" e "gênero". (DAVIS, 2018, p. 99).

Outro conceito importante de Hill Collins (2016), mas somente utilizado em nossas análises muito recentemente, é o de outsider within. O exemplo emblemático utilizado pela autora é o da empregada doméstica, que na condição de outro, racializado e inferiorizado, convive e, portanto, compreende os códigos e as dinâmicas cotidianas da vida das famílias de classes médias e das elites brancas sem que seja parte dela. Essa condição permitiu e permite que as trabalhadoras domésticas possam ver a elite branca a partir de outra perspectiva, não acessível a mulheres e homens brancos, nem a homens negros.

A posição de outsider within ocupada pelas trabalhadoras domésticas reflete, por um lado, a configuração de uma subjetividade feminina negra marcada pela negação, quer seja da infância, do afeto, da convivência familiar e dos direitos de cidadania assegurados pelo Estado e, por outro, indica uma permanente luta por resistir e (re)existir, no sentido de reinventar a si mesma4. Essa posição subalternizada se configura como um espaço importante para

\footnotetext{
${ }^{4}$ Sobre o conceito de (re)existir, ver Adolfo Alban (2013).
} 
observar a realidade. Collins (2000) destaca o modo como a literatura e o feminismo negro têm aproveitado esses insights (FIGUEIREDO, 2016).

O momento atual é caracterizado também pela recuperação das contribuições femininas e feministas negras, como Carolina Maria de Jesus, Lélia Gonzalez e Beatriz Nascimento, dentre outras. Provavelmente Lélia Gonzalez é a autora mais citada por análises feministas recentes. O pioneirismo de Lélia, ao analisar as categorias de gênero, raça e classe, articulando-as com o projeto de identidade e cultura nacional, mostra o grande escopo da sua reflexão teórica.

No seu artigo pioneiro "Racismo e sexismo na cultura brasileira" (1983), em que busca entender a neurose da sociedade brasileira, expressa por intermédio de uma relação de amor e ódio vivenciada pelos negros, denuncia as representações submissas e sexualizadas das mulheres negras, reveladas por meio de três figuras emblemáticas: a mãe-preta, a mulata e a trabalhadora doméstica. Tudo isso contribui para o estabelecimento de regras cotidianas pautadas no desrespeito e na exploração dos corpos, do tempo e da negação do direito à vida "privada" das trabalhadoras domésticas (FIGUEIREDO, 2011).

No referido texto, a autora afirma que "o lixo vai falar", questionando não apenas o fato de os negros serem descritos e representados por outros no universo acadêmico, reivindicando um lugar de legitimidade e autoridade dado pela experiência, como também denuncia as representações submissas e sexualizadas das mulheres negras na cultura brasileira, reveladas através da figura da mãe-preta, da mulata e da empregada doméstica.

Nos últimos anos tem sido ampliado o arcabouço teórico utilizado no Brasil, incluindo as contribuições de autoras africanas e afrodiaspóricas, a exemplo de Oyèrónkẹ Oyěwùmí (2017), que questiona a naturalização da categoria de mulher e gênero, considerando-os como conceitos que refletem a experiência ocidental no mundo, rejeitando o sistema sexo/gênero; e Grada Kilomba (2019), que introduz uma reflexão sobre a mulher negra ser o "outro do outro", numa efetiva alusão a Simone de Beauvoir.

Do ponto de vista das contribuições mais recentes, destacamos a utilização do conceito de protagonismo feminino negro e mais ainda da categoria 
de empoderamento feminino nas suas diferentes acepções nas análises. Cecília Sardenberg é uma das primeiras autoras a definir o empoderamento:

Para nós, feministas, o empoderamento de mulheres é o processo da conquista da autonomia, da autodeterminação. E trata-se, para nós, ao mesmo tempo, de um instrumento/meio e um fim em si próprio. O empoderamento das mulheres implica, para nós, na libertação das mulheres das amarras da opressão de gênero, da opressão patriarcal. Para as feministas latino-americanas, em especial, o objetivo maior do empoderamento das mulheres é questionar, desestabilizar e, por fim, acabar com o a ordem patriarcal que sustenta a opressão de gênero. (SARDENBERG, 2008, p. 3).

Já Silvana Bispo considera que:

O empoderamento, na perspectiva ativa do feminismo negro, não diz respeito apenas às mulheres, mas à comunidade negra como um todo, pois, o racismo, de forma diferenciada, afeta a todas e todos. Dessa forma, não há como lutarmos pela autonomia das mulheres negras, sem que sejam incluídas as variáveis que marginalizam, também, os homens que são vitimados pelo racismo. Nesse contexto, as inter-relações entre estruturas de dominação e seus efeitos na vida cotidiana dos indivíduos são intersecções que precisam estar no panorama das discussões sobre política racial negra e de gênero, de modo que, se possa combatê-las a partir de seus aspectos subalternizadores. (BISPO, 2011, p. 120)

Há também os processos de empoderamento que passam necessariamente pelo corpo feminino e pela estética negra, as marchas do empoderamento crespo são exemplos paradigmáticos desse processo (LOPES, 2017).

Nesse sentido, constatamos o modo como o empoderamento, que expressa a busca por autonomia e autodefinição de grupos que historicamente ocupam a posição inferior na relação desigual de poder, são transformados da perspectiva neoliberal. O empoderamento neoliberal é o empoderamento individual, aquele narrado da perspectiva de mulheres isoladamente, mulheres deslocadas de qualquer mobilização coletiva; são as que arcam com toda a responsabilidade da casa, dos filhos e da família e que fazem isso, sem absolutamente nenhum apoio familiar, assim como não cobram nada do Estado, sequer pleiteiam uma creche para deixar os seus filhos enquanto trabalham, mas 
são capazes de cuidar da casa e da prole enquanto trabalham em casa, assumido a sobrecarga de trabalho. Esse sentido de empoderamento se alinha perfeitamente ao projeto neoliberal, já que é centrado no indivíduo.

\section{Posicionalidade, lugar de fala e o ponto de vista negro}

A produção acadêmica negra posicionada, ativista e engajada, principalmente a de jovens intelectuais negras e negros, prioriza a produção de trabalhos acadêmicos cujo centro são suas experiências. Sabemos, contudo, que essa produção não é vivenciada sem tensão no meio acadêmico. Por isso mesmo, há um discurso que desqualifica a produção acadêmica posicionada, referindose a ela como senso comum ou adjetivando-a como militante, já que é interessada, por isso mesmo supostamente menos científica, porque desafia o mito da neutralidade axiológica.

Com referência ao senso comum, Boaventura (1989), nos ajuda ao propor uma reconciliação entre ciência e senso comum. O autor nos mostra que o discurso científico moderno se estabeleceu a partir de uma ruptura com o senso comum.

O senso comum é um "conhecimento" evidente que pensa o que existe tal como existe e cuja função é reconciliar a consciência comum consigo própria. É, pois, um pensamento necessariamente conservador e fixista. A ciência, para se constituir, tem de romper com estas evidências e com o "código de leitura" do real que elas constituem [...]. (BOAVENTURA, 1989, p. 34).

Ainda de acordo com Boaventura:

O senso comum, enquanto conceito filosófico, surge no século XVIII e representa o combate ideológico da burguesia emergente contra o irracionalismo do ancien régime. [...] Trata-se de um senso que se pretende natural, razoável, prudente, um senso que é burguês e que, por uma dupla implicação se converte em senso médio, em senso universal [...]. (BOAVENTURA, 1989, p. 39).

Numa sociedade de classe, "[...] tal vocação não pode deixar de assumir um viés conservador e preconceituoso, que reconcilia a consciência com a injustiça, naturaliza as desigualdades e mistifica o desejo de transformação" 
(BOAVENTURA, 1989, p. 39). Observem o que ocorre em nossa sociedade com relação à crença de oportunidades entre negros e brancos, para não falar do mito cambaleante, mas ainda resistente, da democracia racial. Contudo, não é exatamente de reprodutores desse senso comum de que somos acusados, pois estes são reproduzidos sob o rótulo de ciência. Nossas produções acadêmicas são desqualificadas com 0 pressuposto de que recuperamos/inserimos/admitimos o senso comum dos movimentos sociais.

Por fim, Boaventura (1989) propõe uma reconciliação dada através de uma dupla ruptura epistemológica, um trabalho de transformação tanto do senso comum como da ciência para criar uma forma de "conhecimento, uma configuração de conhecimento que sendo prático não deixará de ser esclarecido."

Nesse sentido, uma epistemologia insubmissa feminista negra é aquela que propõe uma reconciliação com o senso comum, nos termos colocados por Boaventura, visto que propõe uma ruptura com o senso comum que naturaliza as desigualdades, ao mesmo tempo em que recupera parte dos discursos produzidos pelos movimentos sociais.

Nós, feministas negras, temos explorado essa perspectiva epistemológica de ponto de vista afrocentrado (COLLINS, 1990), destacando as questões relacionadas às implicações da posicionalidade na produção do conhecimento. Como dito anteriormente, Collins (1990) considera que o ponto de vista das mulheres negras é um lugar privilegiado, um lugar historicamente construído e através do qual é possível observar/compreender aspectos importantes do grupo quando se é parte dele. Experiência é um conceito fundamental para a nossa perspectiva epistemológica.

O grupo Modernidade/Colonialidade tem estabelecido uma clara relação entre a colonialidade do poder e a colonialidade do saber, nos diferentes âmbitos sociais, assim como no espaço acadêmico e na produção e legitimidade do conhecimento. De acordo com Anibal Quijano (1992), as independências nos países latino-americanos ocorreram sem uma transformação nas estruturas sociais, políticas e econômicas do período colonial, o que caracterizou as sociedades latino-americanas com uma independência sem descolonização, 
pois os brancos-mestiços se mantiveram na mesma posição elevada na hierarquia racial dos países da América Latina.

A colonialidade do saber pode ser definida brevemente pela relação de poder e saber que se estabelece em todas as dimensões da cultura, a partir de uma lógica e de uma visão de mundo europeia. Nesse sentido, os aportes teóricos caminham, por um lado, na denúncia à violência epistêmica e, por outro, na busca da compreensão, inclusão, validação de outras pedagogias, conteúdos e de sujeitos produtores de conhecimento (OLIVEIRA; CANDAU, 2013).

Maria Lugones, que se autodefine como ativista-teórica-subalterna, e que é mais conhecida entre nós por formular o conceito de colonialidade de gênero, propõe uma epistemologia de fronteira:

[...] que sirvan para cruzar mundos, y no en epistemologías de encrucijadas y fragmentación. Pienso en pedagogías del cruce y en una erótica social. Pienso en comunidades de camaradas solidarias, comunidades donde la solidaridad horizontal está acompañada por un compromiso de aprendernos las unas a las otras. (LUGONES, 2011, p. 791).

Como consequência dessa abordagem, as metodologias precisam ser

[...] metodologías de co-teorización y de colaboración entre académicos, intelectuales comprometidos, investigadores formados en la academia, investigadores comprometidos de "afuera", investigadores de "adentro" e investigadores envueltos en luchas específicas. (LUGONES, 2011, p. 792).

O objetivo dessa proposta é promover um giro decolonial, estreitando o compromisso com o saber que surge

[...] de las insurrecciones de conocimientos subyugados, con los conocimientos alternativos a la modernidad que provienen de comunidades relegadas a la premodernidad, no contemporáneas desde la perspectiva de la modernidad, comunidades en lucha cuyas cosmologías siguen dando significado y coherencia a prácticas comunales. (LUGONES, 2011, p. 798).

As perspectivas teóricas outras, construídas a partir da margem, têm indagado sobre a relação sujeito e objeto. Ochy Curiel considera que para a perspectiva feminista é importante saber: 
¿Quiénes son los sujetos y quiénes son los objetos de nuestras investigaciones? Una de las características de la colonialidad del saber, como señalábamos, es asumir que la otredad y la diferencia colonial, son generalmente los objetos de las investigaciones: mujeres, negras, pobres, indígenas, migrantes, del Tercer Mundo, como si solo a partir de asumirlas como materia prima se hiciera investigación feminista. (CURIEL, 2011, não paginado).

Ao reinvindicar "El desenganche epistemológico", Ochy considera a importância de identificar

[...] conceptos, categorías, teorías que surgen desde las experiencias subalternizadas, que son generalmente producidas colectivamente, que tienen la posibilidad de generalizar sin universalizar, de explicar distintas realidades para romper el imaginario de que estos conocimientos son locales, individuales, sin posibilidad de ser comunicados. (CURIEL, 2011, não paginado).

\section{Considerações finais}

Para concluir, eu diria que a epistemologia insubmissa está muito próxima à lógica que Boaventura define como sociologia das urgências. Uma ciência engajada, formulada a partir de uma perspectiva que busca respostas para os problemas reais enfrentados pela comunidade.

Assim, como sugere Suely Carneiro (2011) em "Enegrecer o feminismo”, a perspectiva descrita quer enegrecer, feminilizar e descolonizar as nossas perspectivas epistêmicas. Isso tem ocorrido através de um movimento que parece centrar as análises a partir da experiência pessoal. Um movimento que quer contar e recontar a história de negros e, principalmente, das mulheres negras no Brasil, não como uma história paralela, mas desmistificando e ampliando a história. Isso ocorreu porque entramos como coletividade muito recentemente nas universidades. Embora haja o reconhecimento de que o conhecimento não é apenas produzido na universidade, foi exatamente a partir da entrada de um maior número de negros e negras nas universidades que esse movimento eclodiu.

Do ponto de vista da atuação prática, essas novas epistemologias têm nos inspirado a criar novas metodologias; temos escrito textos através de cartas, buscado informações através de fontes escritas e divulgadas na internet e, 
definitivamente, temos buscado construir uma reflexão em diálogo com os movimentos sociais.

Embora muitas pesquisas não reivindiquem uma epistemologia feminista e feminista negra decolonial, elas operam com suas perspectivas, tais como a reivindicação do lugar de fala. O reconhecimento do conhecimento advindo dos movimentos sociais contribui para uma reconciliação com o senso comum, como propõe Boaventura (1989).

Consideramos que há, entre a maioria de nós, uma busca por abordagens e temas que façam sentido dentro do cotidiano da comunidade; conhecer para intervir, assim como a busca pelo estabelecimento de relações mais horizontais na pesquisa. Para dar conta dessas novas perspectivas é preciso formular novos conceitos, ferramentas teóricas e metodológicas, pois sabemos que "as ferramentas do senhor jamais destruirão a casa do mestre".

Por fim, gostaria de recuperar a definição de epistemologia proposta por Lugones (2011), visto que a epistemologia insubmissa feminista negra decolonial precisa ser uma epistemologia de fronteira, de encruzilhada e de solidariedade, que forme cada vez mais pesquisadores sensiveis e comprometidos no combate às desigualdades em suas diferentes intersecções.

Nesse sentido, uma epistemologia insubmissa feminista negra decolonial é aquela que se rebela frente às normas previamente estabelecidas, rompendo fronteiras e colocando os sujeitos que historicamente estiveram à margem no centro da produção do conhecimento, no nosso caso em especial, colocando as mulheres negras no centro da produção. Essa proposta está em perfeita consonância com outras levadas a cabo pela perspectiva teórica decolonial e epistemologias outras. Quero dizer que é em diálogo com essas teorias que a produção de mulheres negras tem se articulando e formulado algo em direção ao que definimos como uma epistemologia insubmissa feminista negra decolonial. 


\section{Referências}

AGUIAR, Thais Rodrigues de. Cabelo além da estética: transições capilares e identitárias pelas negras. 2018. 148 f. Dissertação (Mestrado em Antropologia Social) - Universidade Federal de Pelotas, Programa de Pós-Graduação em Ciências Sociais, Pelotas, 2018.

BAIRROS, Luiza. Nossos feminismos revisitados. Revista Estudos Feministas, Florianópolis, ano 3, 2. sem. 1995.

BISPO, Silvana de. Feminismo em debate: reflexão sobre as organizações de mulheres negras em Salvador (1978-1979). 2011. 198 f. Dissertação (Mestrado em Estudos Interdisciplinares sobre Mulher, Gênero e Feminismo) - Faculdade de Filosofia e Ciências Humanas da Universidade Federal da Bahia, Salvador, 2011.

CARNEIRO, Sueli. Construção do outro como não-ser como fundamento do ser. 2005, 339 f. Tese (Doutorado em Educação) - Programa de Pós-Graduação em Educação da Universidade de São Paulo, 2005.

CARNEIRO, Sueli. Enegrecer o feminismo: a situação da mulher negra na América latina a partir de uma perspectiva de gênero. [S.l.: Unifem], 2011. Disponível em: http://www.unifem.org.br/sites/700/710/00000690.pdf. Acesso em: 18 jan. 2016.

COLLINS, Patricia Hill. Black feminist thought: knowledge, consciousness, and the politics of empowerment. Nova York: Routledge, 1990.

COLLINS, Patricia Hill. The black feminist thought. Londres: Routledge, 2000.

COLLINS, Patrícia Hill. Aprendendo com a outsider within: a significação sociológica do pensamento feminista negro. Revista Sociedade e Estado, Brasília, v. 31, n. 1, p. 99-127, jan./abr. 2016.

COLLINS, Patrícia Hill. O que é um nome?: mulherismo, feminismo negro e além disso. Cadernos Pagu, Campinas, n. 51, 2017.

CRENSHAW, Kimberlé. Documento para o encontro de especialistas em aspectos da discriminação racial relativos ao gênero. Estudos Feministas, Florianópolis, v. 10, n. 1, p. 171-189, 2002.

CURIEL, Ochy. Rumo à construção de um feminismo descolonizado. [Ciudad de Guatemala: s.n.], 2011. Disponível em: https://mujeresixchel.wordpress.com/ 2011/10/12/hacia-la-construccion-de-un-feminismo-descolonizado/. Acesso em: 10 out. 2019. 
DAVIS, Angela. Mulheres, raça e classe. São Paulo: Boitempo, 2016.

DAVIS, Angela. Mulheres, Cultura e Política. São Paulo, Boitempo, 2017.

DAVIS, Angela. A liberdade é uma luta constante. São Pauo, Editora Boitempo, 2018

DAVIS, Angela. A democracia da abolição. Rio de Janeiro: Difel, 2019.

FIGUEIREDO, Angela. Condições e contradições do trabalho doméstico em Salvador. In: MORI, Natália; FLEISCHER, Soraya; FIGUEIREDO, Angela; BERNARDINO-COSTA, Joaze; CRUZ, Tãnia. (org.). Tensões e experiências: um retrato das trabalhadoras domésticas de Brasília e Salvador. Centro Feminista de Estudos e Assessoria, Brasília, 2011. p. 89-131.

Figueiredo Angela; GOMES, Patrícia Godinho. Para além dos feminismos: uma experiência comparada entre Guiné-Bissau e Brasil. Revista Estudos Feministas, Florianópolis, v. 24, n. 3, p. 909-927, 2016. Disponível em: http://dx.doi.org/ 10.1590/1806-9584-2016v24n3p909. Acesso em: 2 abr. 2018.

FIGUEIREDO, Angela. Descolonização do conhecimento no século XX. In: SANTIAGO, Ana Rita et al (orgs.). Descolonização do conhecimento no contexto afro-brasileiro. Cruz das Almas: UFRB, 2017a. p. 79-106.

FIGUEIREDO, Angela. Somente um ponto de vista. Cadernos Pagu, Campinas, n. 51, 2017b. Disponível em: http://www.scielo.br/pdf/cpa/n51/1809-4449-cpa18094449201700510017.pdf. Acesso em: 2 jan. 2018.

GONZALEZ, Lélia. Racismo e sexismo na cultura brasileira. Revista Ciências Sociais Hoje, [S.l.]: Anpocs, p. 223-244, 1983.

GONZALEZ, Lélia. Por um feminismo afro-latino. Caderno de formação política do círculo Palmarino, [S. l.]: Batalha de ideias, n. 1., p. 12-21, 2011. Disponível em: https://edisciplinas.usp.br/pluginfile.php/271077/mod_resource/content/1/Por\%2 oum\%20feminismo\%20Afro-latino-americano.pdf. Acesso em: 1 out. 2019.

HARAWAY, Donna. Saberes localizados: a questão da ciência para o feminismo e o privilégio da perspectiva parcial. Cadernos Pagu, Campinas, n. 5, p. 7-42, 1995.

HARDING, Sandra. Feminism \& methodology. Bloomington: Indiana University Press, 1987. 
HOLANDA, Heloísa Buarque de. O Grifo é meu. In: HOLANDA, Heloísa Buarque de (org). Explosão feminista: arte, cultura e política. São Paulo: Companhia das Letras, 2018.

KILOMBA, Grada. Memórias da plantação: episódios de racismo cotidiano. Rio de Janeiro: Cobogó, 2019.

LOPES, Dailza Araújo. Ciberativismo como estratégia política:isepijum estudo sobre grupos de mulheres negras crespas e cacheadas no facebook e em Salvador/BA. Salvador: POSAFRO/UFBA, 2017. 161 f. Mimeografado.

LUGONES, Maria. Hacia metodologías de la decolonialide: conocimientos y prácticas políticas: reflexiones desde nuestras prácticas de conocimiento situado. Chiapas: CIESAS: UNICACH: PDTG-UNMSM, ílepipi2011. p. 790-813. Tomo II.

MIGNOLO, Walter. Desobediência epistêmica: a opção descolonial e o significado de identidade em política. Cadernos de Letras da UFF, Niterói, n. 34, p. 287-324, 2008. Disponível em:

http://www.cadernosdeletras.uff.br/joomla/images/stories/ edicoes/34/traducao.pdf. Acesso em: 28 ago. 2019. Dossiê: Literatura, língua e identidade

NAIME, Roberto. Epistemologia ambiental. [Mangaratiba: ecodebate], 2018. Disponível em: https://www.ecodebate.com.br/2018/12/06/epistemologiaambiental-artigo-de-roberto-naime/. Acesso em: 20 set. 2019.

OLIVEIRA, Luiz Fernandes de; CANDAU, Vera Maria Ferrão. Pedagogia decolonial y educación anti-racista e intercultural en Brasil. In: WALSH, Catherine.

Pedagogías decoloniales: prácticas insurgents de resistir (re) existir e (re) viver. Equador: Edições Abya-Yala Quito, 2013. p. 275-305. Tomo I. (Série Pensamento Decolonial).

OYĚWÙMÍ, Oyeronké. La invención de las mujeres: una perspectiva africana sobre los discursos occidentales de género. Bogotá: Editorial en la Frontera, 2017.

PONS, Claudia. Outras falas: feminismos na perspectiva de mulheres negras brasileiras. 2012. 383 f. Tese (Doutorado em Estudos de Gênero, Mulher e Feminismo) - Universidade Federal da Bahia, Salvador, 2012.

QUIJANO, Aníbal. Colonialidad y modernidad-racionalidad. In: BONILLO, Heraclio (org.). Los conquistados. Bogotá: Tercer Mundo: Flacso, 1992. p. 437-449. 
sociales: perspectivas latinoamericanas. Buenos Aires: CLACSO, Conselho Latino-americano de Ciências Sociais, Jul. 2000. Disponível em:

http://bibliotecavirtual.clacso.org.ar/ar/libros/lander/quijano.rtf. Acesso em: 20 jan. 2019.

RIBEIRO, Djamila. Lugar de fala: feminismos plurais. São Paulo: Polén, 2017.

SANTOS, Boaventura de Souza. Ciência e senso comum. In: SANTOS, Boaventura de Souza. Introdução a uma ciência pós-moderna. Rio de Janeiro: Graal, 1989. p. 31-45.

SARDENBERG, Cecília M.B. Conceituando "Empoderamento" na Perspectiva Feminista. Transcrição revisada da comunicação oral apresentada no I

Seminário Internacional: Trilhas do Empoderamento de Mulheres - Projeto TEMPO, promovido pelo NEIM/UFBA, em Salvador-Ba, de 5-10 de junho de 2006.

SOJOUNER Truth. E não sou uma mulher? Tradução de Osmundo Pinho, GELEDES, 8 de janeiro de 2014. Disponível em https://www.geledes.org.br/enao-sou-uma-mulher-sojourner-truth. Acesso em 30 de novembro de 2019.

SPIVAK, Gayatri Chakravorty. Pode o subalterno falar? Belo Horizonte: Editora da UFMG, 2010. 